\title{
Influence of Vasoactive Infusions on Body Temperature During Off Pump Coronary Artery Bypass Grafting
}

\author{
Muralidhar Kanchi ${ }^{1}$ Prashanth A. Menon ${ }^{2}$ \\ ${ }^{1}$ Narayana Institute of Cardiac Sciences, Narayana Health City, \\ Bommasandra, Bangalore, Karnataka, India \\ ${ }^{2}$ Department of Neuroanaesthesia, National Institute of Mental \\ Health and Neurosciences, Lakkasandra, Bangalore, India \\ J Card Crit Care TSS 2018;2:19-24
}

\begin{abstract}
Address for correspondence Muralidhar Kanchi, MD, FIACTA, FICA, MBA, FASE, Director (Academic), Senior Consultant and Professor, Anesthesia and Intensive Care, Narayana Institute of Cardiac Sciences, Narayana Health City, \#258/A, Bommasandra Industrial Area, Anekal Taluk, Bangalore 560099, Karnataka, India (e-mail: Muralidhar.kanchi.dr@narayanahealth.org).
\end{abstract}

\section{Abstract}

\section{Keywords}

- coronary artery bypass

- off pump

- hypothermia

- vasoconstrictors

- vasodilators

Introduction Unintentional hypothermia in patients undergoing off pump coronary artery bypass grafting (OPCABG) under general anesthesia (GA) is a known complication. The wide sternotomy wound as well as low ambient operating room temperature further promotes heat loss. The changes in temperature could further be affected by the use of various vasoactive drugs by affecting the thermoregulatory response. This study is aimed to detect the temperature changes and the influence of vasoactive infusions on the temperature in the patients undergoing OPCABG under GA.

Aims The main purpose of this article is to assess the core and skin temperature changes during OPCABG surgery and to assess the effect of vasoactive infusion used intraoperatively on the core temperature

Settings and Design Single center, nonrandomized, open label, observational study. Methods and material After informed consent and ethical clearance from institutional review board, 151 adult patients undergoing elective OPCABG surgeries under GA were included in the study. A common anesthetic protocol and warming strategy was used in all patients. The core temperature measured with a nasopharyngeal probe and the skin temperature measured at the palmar surface of the right index finger were recorded at induction, at 30 minutes intervals thereafter, and at end surgery. The demographic variables and the duration of surgery were also recorded. The type and dose of vasoactive agents used intraoperatively were also recorded. The study population was divided post hoc into groups and subgroups for further analysis.

Results All the patients showed a decrease in core temperature at end surgery. The temperature changes showed an initial exponential decrease in the first hour followed by a gradual decrease subsequently. The peripheral temperature showed a gradual increase from induction to end surgery. The temperature gradients showed a linear decrease with the core temperature and peripheral skin temperature reaching equilibrium at end surgery. The study population was divided into four groups depending on the type of vasoactive drugs received intraoperatively: vasoconstrictor $(V)$, vasodilator $(D)$, mixed vasoconstrictor and vasodilator $(\mathrm{M})$, and no vasoactive drugs $(\mathrm{N})$ group. The patients in the vasoconstrictor group had a higher core temperature at end surgery when compared with vasodilator group. Conclusions OPCABG under GA results in decrease in core temperature. The decrease in temperature is exponential in the initial 1 hour followed by a more gradual decrease. The temperature changes are possibly affected by the vasoactive drugs used intraoperatively. The effect of vasoactive drugs on core temperature is higher when used during the initial exponential decrease in temperature. However, further adequately powered randomized controlled trials may be required to establish these findings.

DOI https://doi.org/

10.1055/s-0038-1671810 ISSN 2457-0206.
Copyright $\odot 2018$ Official Publication of The Simulation Society (TSS), accredited by International Society of Cardiovascular Ultrasound (ISCU).
License terms

(ㅇ) (1) $\odot \circledast$ 


\section{Introduction}

Intraoperative hypothermia which is defined as a core body temperature $<36^{\circ} \mathrm{C}^{1,2}$ is a common occurrence in surgical patients under anesthesia. OPCABG involves a wide sternotomy, with exposure of the heart and great vessels to the external environment. The duration of OPCABG is also considerably long. These factors favor a net loss of heat from the patient to the cold exterior environment. General anesthesia (GA) administered for OPCABG surgeries further blunts the autonomic responses to maintain the core temperature.,4 Thus, OPCABG patients are vulnerable to develop perioperative hypothermia. OPCABG also involves the use of perioperative vasoactive drugs to maintain the hemodynamic stability. These drugs are known to affect the cutaneous blood flow as well as thermogenesis. These factors may affect the net intraoperative thermal balance in OPCABG patients.

The aim of the study was to observe the temperature changes in patients undergoing elective OPCABG under GA and the influence of vasoactive drugs administered in intraoperative period on the core temperature.

The specific objective was to analyze the core temperature and skin temperature at predefined time points in these patients, and also to compare the core temperature changes in various groups and subgroups depending on the administration of vasoactive drugs.

\section{Subjects and Methods}

This was an observational study conducted at a tertiary care cardiac center from January 1, 2014 to October 1, 2014. After ethical clearance from the institutional review board, the study included 151 consenting elective patients undergoing OPCABG under GA.

Adult patients of both sexes were included in the study. Patients aged over 70 years, with thyroid disorders, diabetes mellitus, other endocrine dysfunctions, and fever in the past 2 weeks, with core temperature $>37.5^{\circ} \mathrm{C}$ before induction of anesthesia, and with body mass index (BMI) $>30$ or $<20$ were excluded.

All patients received general anesthesia with endotracheal intubation. Standard anesthetic technique was used, which included premedication with oral diazepam $5 \mathrm{mg}$ 2 hours prior to surgery, anesthetic induction with a combination of midazolam $5 \mathrm{mg}$, fentanyl $5 \mu \mathrm{g} / \mathrm{kg}$, and propofol 30 to $50 \mathrm{mg}$. Endotracheal intubation was performed after the administration of pancuronium bromide and anesthesia was maintained with isoflorane $0.8 \%$ end-tidal concentration, intermittent boluses of fentanyl $2 \mu \mathrm{g} / \mathrm{kg}$, and volume-controlled ventilation.

\section{Intraoperative Temperature Management}

All patients were actively warmed with water mattress with the temperature set at $42^{\circ} \mathrm{C}$. Forced air warming devices (Bair hugger) set at $38^{\circ} \mathrm{C}$ was also used to warm patients throughout the surgery. All intravenous fluids were warmed to $38^{\circ} \mathrm{C}$.
Ambient operating room (OR) temperature was maintained at 18 to $20^{\circ} \mathrm{C}$. A circle system with a soda lime canister with a heat and moisture exchanger at patient end of the circuit was used in all patients. A gas flow of 1 to $2 \mathrm{~L} / \mathrm{min}$ was used in all patients. Ventilation was adjusted to maintain an end-tidal carbon dioxide concentration of 35 to $40 \mathrm{~mm} \mathrm{Hg}$.

\section{Monitoring}

Oxygen saturation, arterial blood pressure, end-tidal carbon dioxide, end-tidal anesthetic gas concentration, central venous pressure, urine output, electrocardiogram, temperature, and arterial blood gases were monitored in all patients.

\section{Measurements}

A nasopharyngeal probe was used to measure the core temperature. Skin probe placed on the palmar surface of right index finger was used to measure peripheral temperature. Core temperature, peripheral temperature, and the core to peripheral temperature gradients were recorded every 30 minutes from induction of anesthesia. The readings at end surgery were also recorded. Patient variable age, sex and BMI, as well as the duration of the surgery were also recorded.

\section{Vasoconstrictors and Vasodilators}

Dilution for infusion was adrenaline (ADR) $1 \mathrm{mg}$ in $50 \mathrm{~mL}$ normal saline (NS), noradrenaline (NORAD) $2 \mathrm{mg}$ in $50 \mathrm{~mL}$ NS, dobutamine (DOB) $200 \mathrm{mg}$ in $50 \mathrm{~mL}$ NS and nitroglycerine (NTG) $50 \mathrm{mg}$ in $50 \mathrm{~mL} \mathrm{NS}$, respectively.

The choice, rate, and timing of the vasoactive infusions were at the discretion of the consultant anesthesiologist and surgeon of the respective OR. Post hoc patients were divided into groups and subgroups. Patients receiving only vasoconstrictors (i.e., ADR or NORAD) intraoperatively were grouped as group $V$. Patients receiving only vasodilator drugs (i.e., DOB/NTG) intraoperatively were grouped as group D. Patients administered both vasoconstrictors and vasodilators were grouped as group M. Patients who received neither vasoconstrictors nor vasodilators were grouped as group $\mathrm{N}$.

Patients in group $\mathrm{V}$ were also divided into subgroups ADR (those receiving ADR) and NORAD (those receiving NORAD). Similarly, the group D was subdivided into subgroups: DOB (those receiving dobutamine) and NTG (those receiving nitroglycerine)

The total dose and mean rate of infusion of vasoactive drugs administered intraoperatively were recorded for patients in group $\mathrm{V}$ and group $\mathrm{D}$.

\section{Statistics}

\section{Sample Size}

Sample size was calculated based on the magnitude of temperature changes observed in OPCABG in previous studies. Expected change in core temperature during OPCABG was within $10 \%{ }^{5,6,7}$ Therefore, applying the formula:

$$
n=Z 21-\alpha / 2 p(1-p)
$$

$d 2$

where $p$ is the expected proportion, $d$ is the absolute precision, and $1-\alpha / 2$ is the desired confidence level. 
By substituting in the formula for a change in temperature of $10 \%$, absolute precision of $5 \%$, and a confidence interval of $95 \%$, the minimum required sample size is 138 .

\section{Statistical Analysis}

The statistical analysis was done by using STATA 11.1 (StataCorp LLC). The continuous variables of age, duration, core temperature, peripheral temperature, and temperature gradient at different time points of surgery and the total dose of vasoconstrictors and vasodilators were expressed as mean and standard deviation. Students paired $t$-test was used for core temperature, peripheral temperature, and temperature gradient at different time points and end of surgery for group analysis. Students paired $t$-test was used for core temperature, peripheral temperature, and temperature gradient at different time points for subgroup analysis ( $p<0.05$ considered as statistically significant).

\section{Results}

A total of 151 patients were included in the study. About $58 \%$ of patients were males and the remaining $42 \%$ were females. The demographic data and patient variables are listed in the - Table 1. The study population was divided into groups and subgroups (-Table $\mathbf{1}$ ).

All patients showed a decrease in core temperature $<36^{\circ} \mathrm{C}$ at end surgery ( - Table 2 ). The mean core temperature at end surgery was $35.29 \pm 0.24^{\circ} \mathrm{C}$. The fall in core temperature followed a characteristic pattern. The decrease in core temperature was rapid in the first hour after induction. This was followed by a more gradual reduction in the core temperature ( - Fig. 1)

The skin temperature showed a near linear gradual increase from $34.7 \pm 0.08 \mathrm{C}$ at induction to $35.22 \pm 0.2 \mathrm{C}$ at end surgery.

The temperature gradient decreased from $2.03 \pm-0.12 \mathrm{C}$ at induction to $0.06 \pm 0.08 \mathrm{C}$ at end surgery.

The study population was divided in four group-group $\mathrm{V}$, group $\mathrm{D}$, group $\mathrm{M}$, and group $\mathrm{N}$-depending on the administration of vasoactive drug infusion during the surgery.
Patients in group $\mathrm{V}$ had higher core temperature of 35.50 $\pm 0.21^{\circ} \mathrm{C}$ at end surgery. Patients in group $\mathrm{D}$ had the lowest end surgery core temperature of $34.97 \pm 0.13^{\circ} \mathrm{C}$ ( - Table 3 ). Subgroups ADR and NORAD showed a similar trend in core temperature fall; however, the core temperatures were higher in group ADR when compared with subgroup NORAD at all time points ( - Table 4 ).

Subgroups DOB and NTG showed similar trends in core temperature changes; however, the core temperature was lower in NTG subgroup when compared with subgroup DOB at all time points (-Fig. 2).

The mean rate of infusion of ADR and NORAD was $2.2 \pm$ $0.38 \mu \mathrm{g} / \mathrm{min}$ and $10.6 \pm 0.113 \mu \mathrm{g} / \mathrm{min}$, respectively. The mean rate of infusion of DOB and NTG was $259.3 \pm 41.32 \mu \mathrm{g} / \mathrm{min}$ and $55.2 \pm 13.4 \mu \mathrm{g} / \mathrm{min}$, respectively.

The mean cumulative dose of the vasoactive drug ADR, NORAD, DOB, and NTG was $474.4 \mu \mathrm{g}, 369 \mu \mathrm{g}, 58.5 \mathrm{mg}$, and $12.342 \mathrm{mg}$, respectively.

\section{Discussion}

Unintentional hypothermia in surgical patients is not uncommon. Depression of central and peripheral thermoregulatory compensation may predispose patients under anesthesia to hypothermia. Redistributive heat loss under anesthesia is due to alteration in the cutaneous blood flow. Cutaneous blood flow determines the flow of heat between core compartment and peripheral compartment. GA lowers the threshold temperature at which thermoregulatory vasoconstriction occurs.

Thus, heat flows from the warmer core compartment to the peripheral compartment. This flow of heat continues till equilibrium is reached or till the thermoregulatory vasoconstriction supervenes.

In this study, 151 patients undergoing elective OPCABG under GA were studied. The ambient OR temperature, age of the patient, BMI, and duration of surgery were comparable in all patients. Intraoperative thermal management, ambient OR temperature, and the anesthetic technique used were also comparable in all patients. The nasopharyngeal temperature and skin temperature at induction were also comparable in all patients. It was observed that the core temperature (measured at the nasopharynx) showed a decreasing trend from

Table 1 Patient variables of age sex and BMI in groups and subgroups

\begin{tabular}{|c|c|c|c|c|c|c|c|c|c|}
\hline \multirow[t]{2}{*}{ Variable } & \multirow{2}{*}{$\begin{array}{l}\text { Study } \\
\text { population } \\
n=151\end{array}$} & \multicolumn{4}{|c|}{ Groups } & \multicolumn{4}{|c|}{ Subgroup } \\
\hline & & $\begin{array}{l}D \\
n=34\end{array}$ & $\begin{array}{l}\mathrm{V} \\
n=37\end{array}$ & $\begin{array}{l}M \\
n=17\end{array}$ & $\begin{array}{l}N \\
n=63\end{array}$ & $\begin{array}{l}\text { ADR } \\
n=25\end{array}$ & $\begin{array}{l}\text { NORAD } \\
n=12\end{array}$ & $\begin{array}{l}\text { DOB } \\
n=8\end{array}$ & $\begin{array}{l}\text { NTG } \\
n=26\end{array}$ \\
\hline $\begin{array}{l}\text { Mean age } \\
\text { in years }\end{array}$ & 58.87 & 58.35 & 58.86 & 58.88 & 59.16 & 58.96 & 58.68 & 59.38 & 58.04 \\
\hline $\begin{array}{l}\text { Mean BMI } \\
\text { in } \mathrm{kg} / \mathrm{m}^{2}\end{array}$ & 26.91 & 26.73 & 27.08 & 27.06 & 26.85 & 27.016 & 27.24 & 26.59 & 26.77 \\
\hline $\begin{array}{l}\text { Mean } \\
\text { duration of } \\
\text { surgery in } \\
\text { minutes }\end{array}$ & 217 & 224.65 & 222.75 & 224.53 & 209.84 & 216.48 & 235.83 & 226.63 & 224.04 \\
\hline
\end{tabular}

Abbreviations: ADR, adrenaline; BMI, body mass index; D, vasodilator; DOB, dobutamine; M, mixed; N, none; NORAD, noradrenaline; NTG, nitroglycerine; $\mathrm{V}$, vasoconstrictor. 
Table 2 Mean core temperature and skin temperature with temperature gradient at various time points

\begin{tabular}{|c|c|c|c|c|c|c|c|c|c|c|c|c|c|}
\hline $\begin{array}{l}\text { Time } \\
\text { point }\end{array}$ & $\begin{array}{l}\text { Mean core } \\
\text { temperature } \\
\text { in }^{\circ} \mathrm{C}\end{array}$ & SD & $p$-Value & Max & Min & $\begin{array}{l}\text { Mean } \\
\text { temperature } \\
\text { gradient in }{ }^{\circ} \mathrm{C}\end{array}$ & SD & $p$-Value & $\begin{array}{l}\text { Mean skin } \\
\text { temperature } \\
\text { in }^{\circ} \mathrm{C}\end{array}$ & SD & $p$-Value & Max & Min \\
\hline In & 36.73 & 0.08 & & 36.6 & 36.9 & 2.03 & 0.12 & & 34.7 & 0.08 & & 34.6 & 34.8 \\
\hline 1 & 36.24 & 0.10 & $<0.001$ & 36 & 36.6 & 1.37 & 0.17 & $<0.001$ & 34.86 & 0.14 & $<0.001$ & 34.5 & 35.1 \\
\hline 2 & 35.86 & 0.17 & $<0.001$ & 35.4 & 36.3 & 0.94 & 0.21 & $<0.001$ & 34.92 & 0.19 & $<0.001$ & 34.5 & 35.3 \\
\hline 3 & 35.67 & 0.18 & $<0.001$ & 35.2 & 36.1 & 0.68 & 0.26 & $<0.001$ & 34.98 & 0.26 & $<0.001$ & 34.4 & 35.4 \\
\hline 4 & 35.53 & 0.21 & $<0.001$ & 35 & 36 & 0.48 & 0.33 & $<0.001$ & 35.05 & 0.31 & $<0.001$ & 34.4 & 35.5 \\
\hline 5 & 35.44 & 0.22 & $<0.001$ & 34.9 & 36 & 0.29 & 0.24 & $<0.001$ & 35.16 & 0.22 & $<0.001$ & 34.6 & 35.5 \\
\hline 6 & 35.36 & 0.24 & $<0.001$ & 34.8 & 35.9 & 0.17 & 0.18 & $<0.001$ & 35.18 & 0.19 & $<0.001$ & 34.7 & 35.5 \\
\hline 7 & 35.29 & 0.28 & $<0.001$ & 34.7 & 35.9 & 0.06 & 0.08 & $<0.001$ & 35.21 & 0.22 & $<0.001$ & 34.7 & 35.7 \\
\hline 8 & 35.17 & 0.19 & $<0.001$ & 34.7 & 35.4 & 0.01 & 0.02 & $<0.001$ & 35.15 & 0.18 & $<0.001$ & 34.7 & 35.4 \\
\hline End & 35.29 & 0.24 & $<0.001$ & 34.8 & 35.9 & 0.06 & 0.08 & $<0.001$ & 35.22 & 0.20 & $<0.001$ & 34.7 & 35.7 \\
\hline
\end{tabular}

Abbreviation: SD, standard deviation.

Note: Time points-in = induction, 1 = 30 mins, 2 = 60 mins, 3 = 90 mins....., end = end surgery.

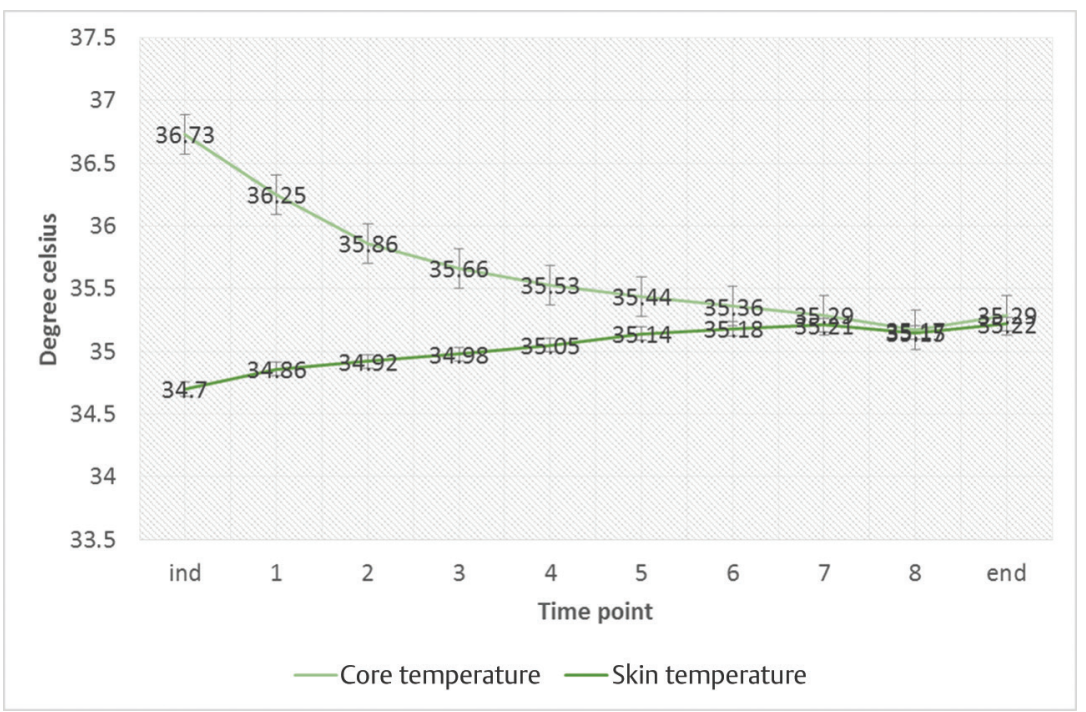

Fig. 1 Core temperature versus skin temperature.

induction to end surgery $(p<0.001)$. This fall in core temperature was steeper in the first 60 minutes after induction. The fall in core temperature in the subsequent intervals was lesser in magnitude.

The skin temperature (measured at right index finger) showed a gradual increase from induction to end surgery. The temperature gradient decreased from induction to end surgery.

The changes in core temperature showed variability within the study population. The mean core temperature was significantly higher in group V (Vasoconstrictor group) at all time intervals, when compared with patients in group $\mathrm{N}$ (none), group $\mathrm{D}$ (vasodilator group), and group $\mathrm{M}$ (mixed vasodilator and vasoconstrictor group).

The core temperature was lowest in the group D (vasodilator group). The change in core temperature reflects the normal trends in heat flow under GA. The variability in the changes in core temperature probably reflects the influence of vasoactive drugs on the cutaneous blood flow and hence the redistributive heat loss. These findings may be suggestive of a reduction in redistributive heat loss with the administration of vasoconstrictor drugs and an increase in the same with vasodilator drugs administered intraoperatively.

The changes in skin temperature showed a statistically significant increase from induction to end surgery. The observed changes in peripheral temperature probably reflect the combined effects of redistributive heat gain in peripheral compartment and also the effect of convective warming. The observed temperature changes were variable with the type of vasoactive drug administered. Patients who received DOB had lower core temperature at all time intervals when compared with patients who received NTG. Similarly, in patients who received ADR, the core 
Table 3 Core temperature in different groups and subgroups

\begin{tabular}{|l|l|l|l|l|l|}
\hline \multirow{2}{*}{ Time point } & \multicolumn{1}{|c|}{ Group D } & \multicolumn{1}{|c|}{ Group M } & \multicolumn{1}{|c|}{ Group N } & \multicolumn{1}{c|}{ Group V } & \multirow{2}{*}{$p$-Value } \\
\cline { 2 - 5 } & \multicolumn{1}{|c|}{ Mean \pm SD } & \multicolumn{1}{|c|}{ Mean \pm SD } & \multicolumn{1}{|c|}{ Mean \pm SD } & Mean \pm SD & \\
\hline C In & $36.73 \pm 0.08$ & $36.75 \pm 0.09$ & $36.73 \pm 0.08$ & $36.74 \pm 0.09$ & 0.563 \\
\hline C1 & $36.16 \pm 0.10$ & $36.33 \pm 0.08$ & $36.21 \pm 0.06$ & $36.29 \pm 0.12$ & $<0.001$ \\
\hline C2 & $35.71 \pm 0.17$ & $35.88 \pm 0.14$ & $35.88 \pm 0.08$ & $35.96 \pm 0.18$ & $<0.001$ \\
\hline C3 & $35.47 \pm 0.17$ & $35.72 \pm 0.17$ & $35.68 \pm 0.08$ & $35.79 \pm 0.19$ & $<0.001$ \\
\hline C4 & $35.28 \pm 0.13$ & $35.61 \pm 0.17$ & $35.54 \pm 0.09$ & $35.71 \pm 0.20$ & $<0.001$ \\
\hline C5 & $35.16 \pm 0.13$ & $35.59 \pm 0.15$ & $35.42 \pm 0.09$ & $35.66 \pm 0.18$ & $<0.001$ \\
\hline C6 & $35.05 \pm 0.14$ & $35.5 \pm 0.16$ & $35.34 \pm 0.08$ & $35.59 \pm 0.20$ & $<0.001$ \\
\hline C7 & $34.95 \pm 0.14$ & $35.45 \pm 0.16$ & $35.34 \pm 0.08$ & $35.52 \pm 0.22$ & $<0.001$ \\
\hline C8 & $34.88 \pm 0.11$ & $35.3 \pm 0.08$ & $35.24 \pm 0.08$ & $35.31 \pm 0.06$ & $<0.001$ \\
\hline C End & $34.97 \pm 0.13$ & $35.44 \pm 0.17$ & $35.29 \pm 0.08$ & $35.50 \pm 0.21$ & $<0.001$ \\
\hline
\end{tabular}

Abbreviation: SD, standard deviation.

Note: Time point $C$ in=induction, $C 1=30$ mins, $C 2=60$ mins, $C 3=90$ mins....C end =end surgery.

Table 4 Core temperature between subgroups ADR vs NORAD and DOB vs NTG

\begin{tabular}{|l|l|l|l|l|l|l|}
\hline \multicolumn{1}{|c|}{ Time point } & ADR & NORAD & & DOB & NTG & \\
\hline & Mean \pm SD & Mean \pm SD & $p$-Value & Mean \pm SD & Mean \pm SD & $p$-Value \\
\hline C In & $36.75 \pm 0.08$ & $36.73 \pm 0.10$ & 0.637 & $36.75 \pm 0.11$ & $36.72 \pm 0.06$ & 0.343 \\
\hline C1 & $36.33 \pm 0.12$ & $36.22 \pm 0.07$ & 0.006 & $36.23 \pm 0.07$ & $36.14 \pm 0.10$ & 0.042 \\
\hline C2 & $36.02 \pm 0.20$ & $35.85 \pm 0.10$ & 0.013 & $33.88 \pm 0.10$ & $35.66 \pm 0.16$ & 0.001 \\
\hline C3 & $35.86 \pm 0.19$ & $35.66 \pm 0.10$ & 0.001 & $35.68 \pm 0.10$ & $35.41 \pm 0.13$ & $<0.001$ \\
\hline C4 & $35.78 \pm 0.20$ & $35.55 \pm 0.09$ & 0.001 & $35.48 \pm 0.10$ & $35.21 \pm 0.13$ & $<0.001$ \\
\hline C5 & $35.74 \pm 0.18$ & $35.52 \pm 0.07$ & $<0.001$ & $35.28 \pm 0.10$ & $35.13 \pm 0.12$ & 0.005 \\
\hline C6 & $35.68 \pm 0.19$ & $35.42 \pm 0.07$ & $<0.001$ & $35.18 \pm 0.10$ & $35.01 \pm 0.13$ & 0.004 \\
\hline C7 & $35.62 \pm 0.20$ & $35.32 \pm 0.07$ & $<0.001$ & $35.08 \pm 0.10$ & $34.91 \pm 0.13$ & 0.004 \\
\hline C8 & - & $35.31 \pm 0.06$ & & $34.97 \pm 0.06$ & $34.85 \pm 0.10$ & 0.122 \\
\hline C End & $35.6 \pm 0.19$ & $35.31 \pm 0.07$ & $<0.001$ & $35.08 \pm 0.10$ & $34.94 \pm 0.12$ & 0.009 \\
\hline
\end{tabular}

Abbreviation: Abbreviations: ADR, adrenaline; DOB, dobutamine; NORAD, noradrenaline; NTG, nitroglycerine; SD, standard deviation.

Note: Time point $\mathrm{C}$ in = induction, $\mathrm{C} 1=30 \mathrm{mins}, \mathrm{C} 2=60 \mathrm{mins}, \mathrm{C} 3=90 \mathrm{mins} . . . \mathrm{C}$ end $=$ end surgery.

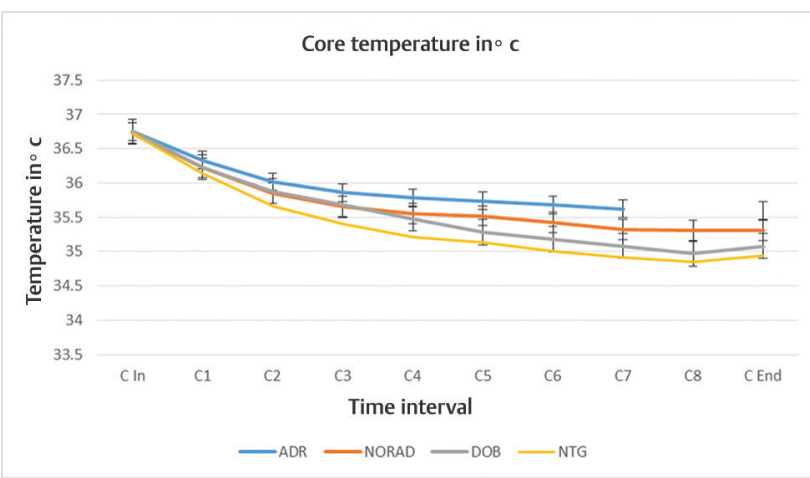

Fig. 2 Temperature changes in subgroups. Abbreviations: ADR, adrenaline; DOB, dobutamine; NORAD, noradrenaline; NTG, nitroglycerine. temperatures were higher than those observed in patients who received NORAD.

The findings of this study corroborate the findings observed by Goldberg and Roe, ${ }^{8,9}$ Matsukawa et al, ${ }^{10}$ and Castillo Monzón et $\mathrm{al}^{11}$ that most patients had a fall in core temperature; however, the degree of fall in temperature varied from these studies in view of the different monitoring sites, thermal management, type of surgery, and duration of surgery. The pattern of temperature fall was similar to that observed by Matsukawa et al, but of a lesser magnitude.

In this study, the core temperatures were comparable to the forced air warming group in study conducted by Zangrillo Alberto et $\mathrm{al}^{5}{ }^{5}$ the actively warmed group in the study conducted by Woo et al, ${ }^{6}$ and Warm-Touch group in the study conducted by Hofer et al. ${ }^{7}$

The core temperature changes observed in group $\mathrm{V}$ were comparable with those observed in study by Ikeda et al $^{12}$ 
on the effect of phenylephrine infusion in oral surgeries under GA. The findings were also comparable and corroborative of the findings in 2008 by Lebedinskiy et $\mathrm{al}^{13}$ on the role of epinephrine in preventing inadvertent prevent intraoperative hypothermia and the study by Jo et $\mathrm{al}^{14}$ who compared the effect of NS and ephedrine infusion in surgical patients under GA.

The temperature changes in group D of this study were comparable with the findings of Vassilieff et $\mathrm{al}^{15}$ on the effect of oral nifedipine in patients undergoing hip arthroplasty. These findings were also similar to the findings by Shitara et $\mathrm{al}^{16}$ who observed that core temperature decreased further in patients receiving DOB infusion. The findings also support the observation made in 1998 by Morioka et $\mathrm{al}^{17}$ that drug-induced modulation of vascular tone influences the intraoperative core temperature.

\section{Limitations of the Study}

- This study was a single center study; thus, a larger multicenter survey and randomized control studies may be necessary to establish the application of the findings in a larger population.

- The timing of administration and the dose of vasoactive drugs were variable in the study population thus adding to confounding effects.

Further research on the effects of vasoactive drugs may be required to confirm the findings.

\section{Conclusion}

Perioperative hypothermia is a known complication in surgeries of long duration like OPCABG. From this study, we conclude that, in OPCABG under GA, the core temperature decreases from induction to end surgery with an initial rapid decrease followed by a gradual decrease. The skin temperature, however, increased gradually from induction to end surgery. Vasoactive drugs might have an influence on the core temperature changes. The vasodilators used perioperatively may further decrease the core temperature, while vasoconstrictor drugs may reduce the magnitude of decrease in core temperature.

\section{Key Message}

In OPCABG, core temperature shows a characteristic exponential fall followed by a more gradual fall, while skin temperature gradually increases. The change in core temperature could possibly be modulated by the type and time of vasoactive drugs administered in intraoperative period.

\section{Conflict of Interest}

None.

\section{References}

1 Lopez M, Sessler DI, Walter K, Emerick T, Ozaki M. Rate and gender dependence of the sweating, vasoconstriction, and shivering thresholds in humans. Anesthesiology 1994;80(4):780-788

2 Heier T, Caldwell JE. Impact of hypothermia on the response to neuromuscular blocking drugs. Anesthesiology 2006;104(5):1070-1080

3 Kurz A, Go JC, Sessler DI, Kaer K, Larson MD, Bjorksten AR. Alfentanil slightly increases the sweating threshold and markedly reduces the vasoconstriction and shivering thresholds. Anesthesiology 1995;83(2):293-299

4 Matsukawa T, Kurz A, Sessler DI, Bjorksten AR, Merrifield B, Cheng C. Propofol linearly reduces the vasoconstriction and shivering thresholds. Anesthesiology 1995;82(5):1169-1180

5 Zangrillo A, Pappalardo F, Talò G, et al. Temperature management during off-pump coronary artery bypass graft surgery: a randomized clinical trial on the efficacy of a circulating water system versus a forced-air system. J Cardiothorac Vasc Anesth 2006;20(6):788-792

6 Woo YJ, Atluri P, Grand TJ, Hsu VM, Cheung A. Active thermoregulation improves outcome of off-pump coronary artery bypass. Asian Cardiovasc Thorac Ann 2005;13(2):157-160

7 Hofer CK, Worn M, Tavakoli R, et al. Influence of body core temperature on blood loss and transfusion requirements during off-pump coronary artery bypass grafting: a comparison of 3 warming systems. J Thorac Cardiovasc Surg 2005;129(4):838-843

8 Goldberg MJ, Roe CF. Temperature changes during anesthesia and operations. Arch Surg 1966;93(2):365-369

9 Goldberg M, Roe C. Temperature changes during anesthesia and operations. Surv Anesthesiol 1967;11(3):234

10 Matsukawa T, Sessler DI, Sessler AM, et al. Heat flow and distribution during induction of general anesthesia. Anesthesiology 1995;82(3):662-673

11 Castillo Monzón C, Candia Arana C, Marroquín Valz H, Aguilar Rodríguez F, Benavides Mejía J, Alvarez Gómez J. Temperature management during the perioperative period and frequency of inadvertent hypothermia in a general hospital. Colombian J Anesthesiol. 2013;41(2):97-103

12 Ikeda T, Ozaki M, Sessler DI, Kazama T, Ikeda K, Sato S. Intraoperative phenylephrine infusion decreases the magnitude of redistribution hypothermia. Anesth Analg 1999;89(2):462-465

13 Lebedinskiy K, Parvanian S, Nikolayev A. Low-dose epinephrine infusion in inadvertent hypothermia prevention during surgery. Eur J Anaesthesiol 2008;25(44):53

14 Jo YY, Kim JY, Kim JS, Kwon Y, Shin CS. The effect of ephedrine on intraoperative hypothermia. Korean J Anesthesiol 2011;60(4):250-254

15 Vassilieff N, Rosencher N, Sessler DI, Conseiller C, Lienhart A. Nifedipine and intraoperative core body temperature in humans. Anesthesiology 1994;80(1):123-128

16 Shitara T, Wajima Z, Ogawa R. Dobutamine infusion modifies thermoregulation during general anesthesia. Anesth Analg 1996;83(6):1154-1159

17 Morioka N, Ozaki M, Sessler D, et al. Preoperative transdermal nitroglycerin decreases redistribution hypothermia after induction of anesthesia. Anesthesiology 1998;89 (Supplement):310A 